\title{
ANALISIS PEMANCANGAN TIANG PADA KONSTRUKSI OFFSHORE PELABUHAN DI PULAU JAWA TERHADAP SCOURING EFFECT
}

\author{
Mega Rukmana ${ }^{1}$ dan Chaidir A. Makarim² \\ ${ }^{1}$ Program Studi Sarjana Teknik Sipil, Universitas Tarumanagara, Jl. Letjen S. Parman No.1 Jakarta \\ Email: megarukmana97@gmail.com \\ ${ }^{2}$ Program Studi Sarjana Teknik Sipil, Universitas Tarumanagara, Jl. Letjen S. Parman No.1 Jakarta \\ Email: chaidir259@gmail.com
}

\begin{abstract}
ABSTRAK
Penggunaan pondasi tiang pancang banyak digunakan pada perencanaan konstruksi dimana bangunan bertemu dengan air seperti bangunan lepas pantai (offshore). Analisis perencanaan yang tepat harus dilakukan agar bangunan lepas pantai terbebas dari kegagalan yang tidak diinginkan. Dalam perencanaannya diperlukan adanya analisis terhadap kemungkinan terjadinya gerusan (scouring) dan energi pemancangan (driveability). Dengan menganalisis hal tersebut pada pondasi tiang, dapat diketahui kapasitas tiang yang lebih tepat lagi untuk digunakan dalam perencanaan konstruksi offshore. Pemancangan tiang dengan menggunakan alat yang tepat juga tidak luput dari peranan pukulan yang diberikan oleh energi hammer. Dengan mengetahui tegangan yang terjadi selama pemancangan tiang, overstress dan overtension pada tiang dapat dihindari. Dari hasil simulasi yang dilakukan dapat dibahas dan diambil kesimpulan tentang integritas dan kapasitas tiang itu sendiri.
\end{abstract}

Kata Kunci: Scouring, Offshore, Kapasitas Tiang, Overstress, Pemancangan Tiang.

\section{PENDAHULUAN}

Di dalam pembangunan proyek konstruksi terdapat berbagai macam proyek konstruksi, mulai dari kontruksi jalan, jembatan, gedung bertingkat tinggi, rumah, dan lain-lain. Setiap konstruksi juga dibagi menjadi dua tahap, yaitu pekerjaan konstruksi struktur bawah dan pekerjaan konstruksi struktur atas. Pekerjaan struktur atas pada sebuah pekerjaan konstruksi biasanya meliputi pekerjaan balok, kolom, pelat lantai, dinding geser, dan tangga. Sedangkan pekerjaan struktur bawah pada sebuah pekerjaan konstruksi biasanya meliputi pekerjaan galian, pekerjaan pondasi, dan pekerjaan basement.

Pekerjaan struktur bawah merupakan pekerjaan yang krusial dikarenakan bangunan yang akan dibangun harus memiliki struktur pondasi yang benar. Pondasi memiliki berbagai tipe yang salah satunya adalah pondasi tiang pancang. Pondasi tiang pancang sudah tidak asing lagi dalam pembangunan sebuah kosntruksi. Tiang pancang bisa terbuat dari beton, baja, dan kayu. Tiang pancang yang terbuat dari baja bukan hanya dapat digunakan pada bangunan gedung tetapi bisa juga digunakan pada konstruksi lepas pantai (offshore).

Pelabuhan merupakan sebuah struktur yang digunakan untuk kegiatan pemerintahan dan kegiatan ekonomi yang dipergunakan sebagai tempat kapal bersandar, berlabuh, naik dan turunnya penumpang, maupun bongkar muat barang. Dikarenakan fungsinya yang vital bagi negara dan masyarakat, diperlukan perencanaan yang mumpuni agar pelabuhan dapat terus digunakan. Tetapi terkadang pelabuhan bisa menjadi tidak reliabel, dikarenakan seringkali terdengar beberapa kasus dimana pelabuhan rusak atau mengalami kegagalan. Hal ini menyebabkan kegiatan yang memerlukan fungsi pelabuhan menjadi terhentikan.

Salah satu penyebab terjadinya kegagalan pelabuhan adalah scouring effect. Peristiwa scouring yang terjadi pada bangunan-bangunan yang bertemu dengan air, seperti pelabuhan, jembatan, maupun bangunan lepas pantai lainnya dapat menyebabkan kerusakan pada pondasi tiang struktur tersebut, mengingat bahwa tanah turut serta dalam memberi ketahanan friksi pada sebuah tiang. Jika tanah tersebut tergerus atau terangkat bersama gelombang air, maka kegagalan pun tidak dapat dihindari.

Tanah selalu mempunyai peranan yang penting dalam pekerjaan konstruksi. Tanah adalah pondasi pendukung suatu bangunan, atau bahan konstruksi dari bangunan itu sendiri. Scouring effect sering menjadi salah satu biang masalah pada tiang bangunan offshore, dikarenakan komponen tiang yang bertemu dengan tanah akan terlihat seperti memiliki lubang. Hal ini yang dapat menyebabkan kegagalan sebuah pelabuhan yang disebabkan oleh penurunan daya dukung tanah akibat tanah yang hilang atau terangkat karena gerusan oleh air disekitar tiang. 
Beban pada sebuah tiang dalam bangunan pelabuhan tidak hanya dapat menerima momen guling dan beban aksial, tetapi juga beban lateral. Pada bangunan pelabuhan, beban lateral muncul akibat adanya gelombang air, gempa, maupun angin. Kelebihan beban lateral pada tiang dapat menyebabkan berbagai masalah pada jembatan salah satunya kegagalan tiang. Kegagalan ini juga dapat disebabkan oleh pemancangan tiang yang kurang baik di lapangan, seperti pemilihan hammer yang kurang tepat sehingga tegangan yang terjadi pada tiang melebihi tegangan ijin. Oleh sebab itu analisis dan desain dalam pembangunan konstruksi offshore merupakan hal yang penting untuk memastikan bahwa bangunan dapat mempertahankan kestabilannya sesuai dengan umur rencana.

Analisis kapasitas lateral pada tiang dapat dimodelkan dengan menggunakan program LPILE. Hasil dari perhitungan pada program LPILE adalah gaya yang dapat terjadi pada tiang dan tahanan tiang tersebut. Sedangkan untuk simulasi pemancangan dilakukan pada program GRLWEAP untuk mengetahui efek dari jenis hammer serta tegangan yang terjadi selama pemancangan.

\section{Tiang Pancang}

Tiang pancang merupakan salah satu dari berbagai jenis fondasi dalam yang dipasang dengan cara dipancang. Tiang pancang dapat terbuat dari kayu, beton, baja, serta campuran beton dan baja (komposit). Penggunaan fondasi tiang pancang sebagai posisi bangunan apabila tanah yang berada dibawah dasar bangunan tidak mempunyai daya dukung (bearing capacity) yang cukup untuk memiliki berat bangunan dan beban yang bekerja padanya (Sardjono, 1984)..

\section{Tanah}

Menurut Braja M Das (1995), tanah umumnya dapat disebut sebagai kerikil (gravel), pasir (sand), lanau (silt), atau lempung (clay), tergantung pada ukuran partikel yang paling dominan pada tanah tersebut. Kerikil (gravel) adalah kepingan-kepingan dari batuan yang terkadang juga mengandung partikel-partikel mineral quartz, feldspar, dan mineral-mineral lain. Pasir (sand) sebagian besar terdiri dari mineral quartz dan feldspar. Butiran dari mineral yang lain mungkin juga masih ada pada golongan ini. Lanau (silts) sebagian besar merupakan fraksi mikroskopis (berukutan sangat kecil) dari tanah yang terdiri dari butiran-butiran quartz yang sangat halus, dan sejumlah partikel berbentuk lempengan-lempengan pipih yang merupakan pecahan dari mineral-mineral mika. Lempung (clays) sebagian besar terdiri dari partikel mikroskopis dan submikroskopis (tidak dapat dilihat dengan jelas bila hanya dengan mikroskopis biasa) ynag berbentuk lempengan-lempengan pipih dan merupakan partikel-partikel dari mika, mineral-mineral lempung (clay minerals), dan mineral-mineral yang sangat halus lainnya.

\section{Scouring}

Gerusan (scouring) adalah proses erosi dan deposisi yang terjadi karena perubahan aliran di sungai. Perubahan ini karena adanya halangan pada aliran sungai yang berupa bangunan sungai seperti pilar jembatan. Bangunanbangunan ini dipandang dapat merubah geometri alur serta pola aliran, yang selanjutnya diikuti dengan timbulnya gerusan lokal di sekitar bangunan. Adanya pilar jembatan pada suatu ruas sungai dapat menyebabkan perubahan pola aliran yang menimbulkan gerusan lokal di sekitar pilar sehingga menyebabkan penurunan elevasi dasar di sekitar pilar. Sehubungan dengan adanya gerusan lokal yang dapat membahayakan bangunan sungai (pilar, abutment, krib dan sebagainya) berupa keruntuhan pada bangunan tersebut (Lujitno, 2015).

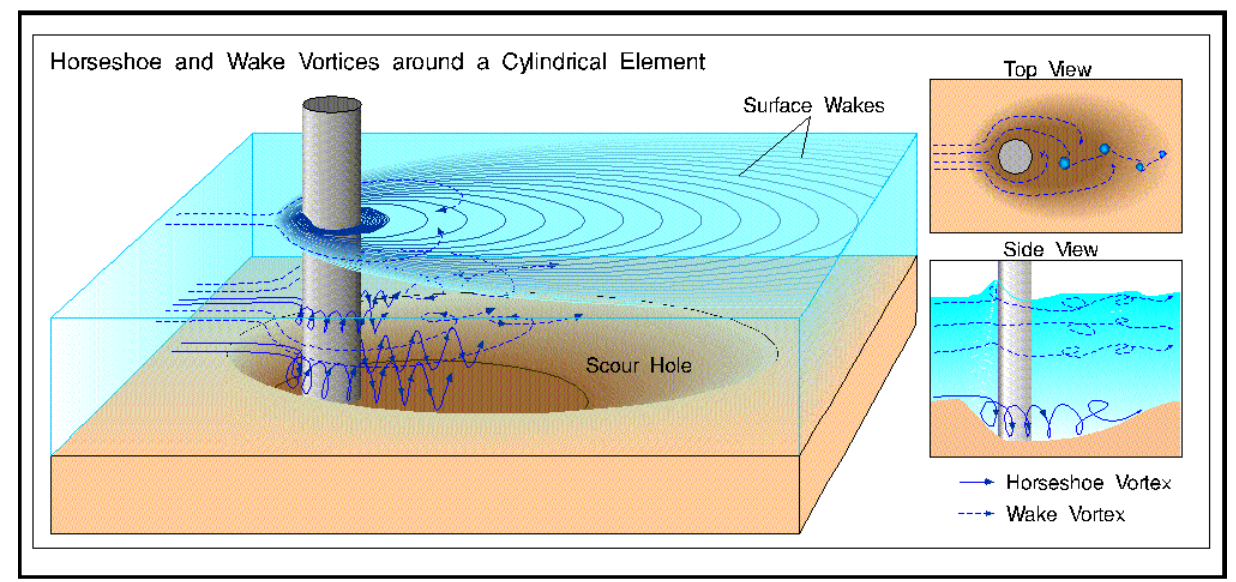

Gambar 1. Ilustrasi Terjadinya Scouring pada Tiang 


\section{METODOLOGI PENELITIAN (SECTION)}

Penelitian ini dilakukan berdasarkan hasil analisis dengan bantuan program LPILE dan GRLWEAP. Dalam melaksanakan analisis, langkah-langkah yang ditempuh penulis digambarkan melalui diagram alir penelitian seperti pada Gambar 1.

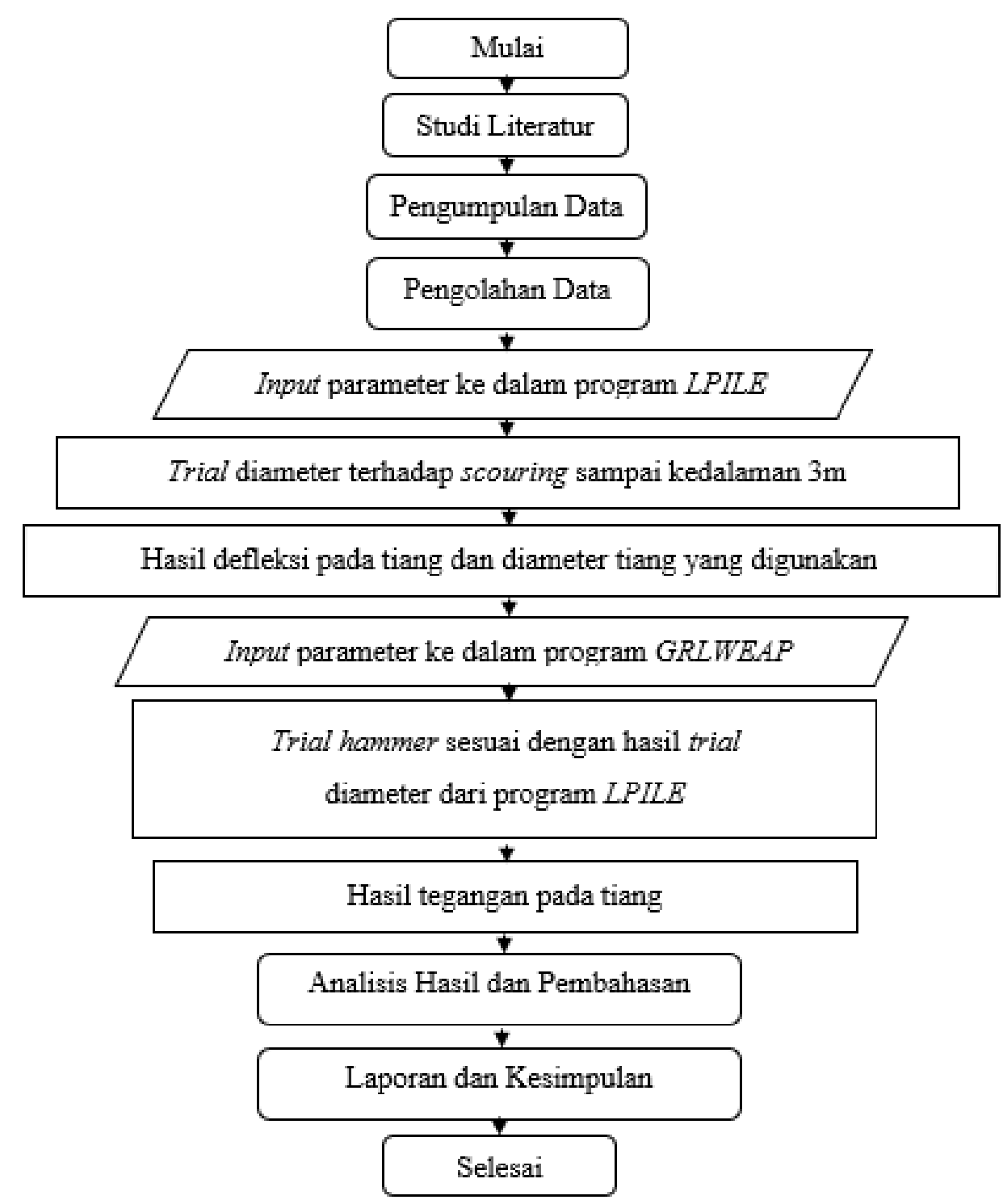

Gambar 2. Diagram Alir Penelitian

\section{Studi Literatur}

Penelitian dimulai dengan mengumpulkan teori untuk analisis pemancangan tiang pada konstruksi pelabuhan di pulau Jawa terhadap scouring effect berupa buku, jurnal, penelitian, disertasi, dan persyaratan defleksi pada tiang.

\section{Pengumpulan dan Pengolahan Data}

Data-data awal yang telah dikumpulkan adalah berupa data tanah bore log, data tiang, dan data hammer. Tiang yang digunakan adalah tiang pancang pipa baja (steel pipe pile) open ended dengan diameter $600 \mathrm{~mm}$, tebal $16 \mathrm{~mm}$, panjang total $30 \mathrm{~m}$, serta mutu baja BJ37. Untuk data tiang lainnya dapat dilihat pada Tabel 4. Hammer yang digunakan adalah tipe KOBE K 25. Data tanah yang didapatkan berupa data bore $\log 1$ dan bore $\log 2$ lalu diambil nilai desainnya berdasarkan korelasi terhadap nilai N-SPT. Data tanah yang akan digunakan dapat dilihat pada Tabel 3. Untuk pembebanan pada kepala tiang digunakan beban maksimum yang dapat diterima oleh masing-masing ukuran tiang. 
Tabel 1. Data Bore Log 1

\begin{tabular}{ccc}
\hline \multicolumn{3}{c}{ Bore Log 1} \\
\hline Depth $(\mathrm{m})$ & Soil & N-SPT \\
\hline $0-1$ & Sand & 7 \\
\hline $1-2$ & Sand & 9 \\
\hline $2-4$ & Sandy Clay & 11 \\
\hline $4-6$ & Clay & 6 \\
\hline $6-8.5$ & Clayey Silt & 5 \\
\hline $8.5-10$ & Clay & 4 \\
\hline $10-12$ & Clay & 7 \\
\hline $12-14$ & Silty Clay & 4 \\
\hline $14-16$ & Clayey Silt & 10 \\
\hline $16-18$ & Clay & 5 \\
\hline $18-20$ & Silt & 8 \\
\hline $20-22$ & Silt & 13 \\
\hline $22-24$ & Silt & 50 \\
\hline $24-28$ & Cemented Silt & 50 \\
\hline $28-30$ & Cemented Clay & 50 \\
\hline
\end{tabular}

Tabel 2. Data Bore Log 2

\begin{tabular}{ccc}
\hline \multicolumn{3}{c}{ Bore Log 2} \\
\hline Depth $(\mathrm{m})$ & Soil & N-SPT \\
\hline $0-1$ & Sand & 12 \\
\hline $1-2$ & Sand & 8 \\
\hline $2-4$ & Sand & 10 \\
\hline $4-6$ & Sand & 7 \\
\hline $6-8$ & Sand & 5 \\
\hline $8-10$ & Silty Clay & 4 \\
\hline $10-12$ & Clayey Silt & 4 \\
\hline $12-14$ & Clayey Silt & 3 \\
\hline $14-16$ & Clayey Silt & 11 \\
\hline $16-18$ & Clay & 9 \\
\hline $18-20$ & Clay & 8 \\
\hline $20-22$ & Silty Clay & 10 \\
\hline $22-24$ & Silt & 41 \\
\hline $24-26$ & Cemented Silt & 50 \\
\hline $26-28$ & Silt & 50 \\
\hline $28-30$ & Cemented Sand & 50 \\
\hline & &
\end{tabular}


Tabel 3. Data Tanah Desain

\begin{tabular}{cccccc}
\hline \multicolumn{7}{c}{ Data Tanah Desain } \\
\hline Depth $(\mathrm{m})$ & Soil & N-SPT & $\begin{array}{c}\text { Berat Jenis } \\
\gamma\left(\mathrm{kN} / \mathrm{m}^{3}\right)\end{array}$ & $\begin{array}{c}\text { Sudut Geser } \\
\phi^{\prime}(\text { derajat })\end{array}$ & $\begin{array}{c}\text { Undrained } \\
\text { Cohesion } \\
\text { Cu }\left(\mathrm{kN} / \mathrm{m}^{2}\right)\end{array}$ \\
\hline $0-4$ & Sand & 9 & 16 & 34 & - \\
\hline $4-8$ & Sand & 6 & 15 & 30 & - \\
\hline $8-14$ & Clay & 5 & 14 & - & 3 \\
\hline $14-20$ & Clay & 8 & 16 & - & 4.5 \\
\hline $20-22$ & Clay & 11 & 17 & - & 7.5 \\
\hline $22-24$ & Clay & 45 & 21 & - & 29 \\
\hline $24-28$ & Clay & 50 & 22 & - & - \\
\hline $28-30$ & Sand & 50 & 22 & 45 & 35 \\
\hline
\end{tabular}

Tabel 4. Data Awal Tiang dan Hammer

\begin{tabular}{cc}
\hline \multicolumn{2}{c}{ Data Awal Tiang dan Hammer } \\
\hline Jenis tiang & Steel pipe pile (open ended) \\
\hline Bahan tiang & Baja \\
\hline Panjang tiang & $30 \mathrm{~m}$ \\
\hline Tegangan leleh (fy) & $240 \mathrm{MPa}$ \\
\cline { 2 - 2 } & $240000 \mathrm{kN} / \mathrm{m} 2$ \\
\hline Modulus Elastisitas (E) & $200000 \mathrm{MPa}$ \\
\hline Diameter tiang & $200000000 \mathrm{kN} / \mathrm{m} 2$ \\
\hline Tebal tiang & $600 \mathrm{~mm}$ \\
\hline Tinggi bebas tiang & $16 \mathrm{~mm}$ \\
\hline Tinggi air bebas & $2.5 \mathrm{~m}$ \\
\hline Hammer & $2.5 \mathrm{~m}$ \\
\hline
\end{tabular}

\section{Analisis dengan Program LPILE}

Analisis dengan program LPILE dilakukan untuk mengetahui kapasitas lateral dan defleksi tiang yang terjadi akibat adanya efek gerusan sampai pada kedalaman 3 m.Pada program ini dilakukan trial diameter tiang sampai didapatkan hasil kapasitas dan defleksi tiang yang memenuhi syarat. Untuk mendapatkan hasil kapasitas dan defleksi tiang, dilakukan dengan input parameter tiang yang akan digunakan, lalu input parameter tanah, dan input pembebanan maksimum pada kepala tiang. Setelah itu dilakukan run analysis dan diperoleh kapasitas serta defleksi tiang.

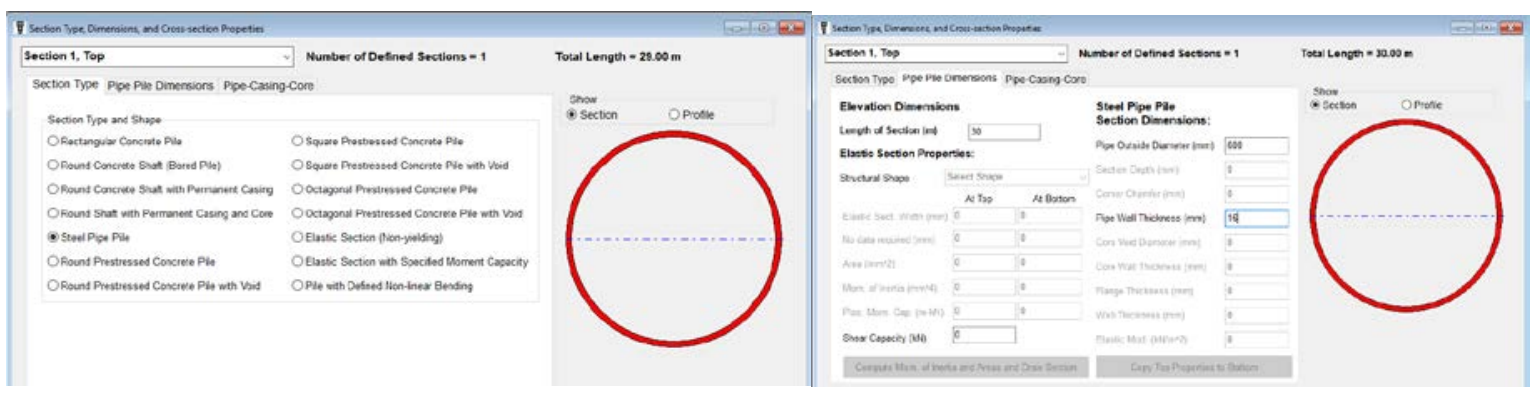

Gambar 3. Input Parameter Tiang pada Program LPILE 


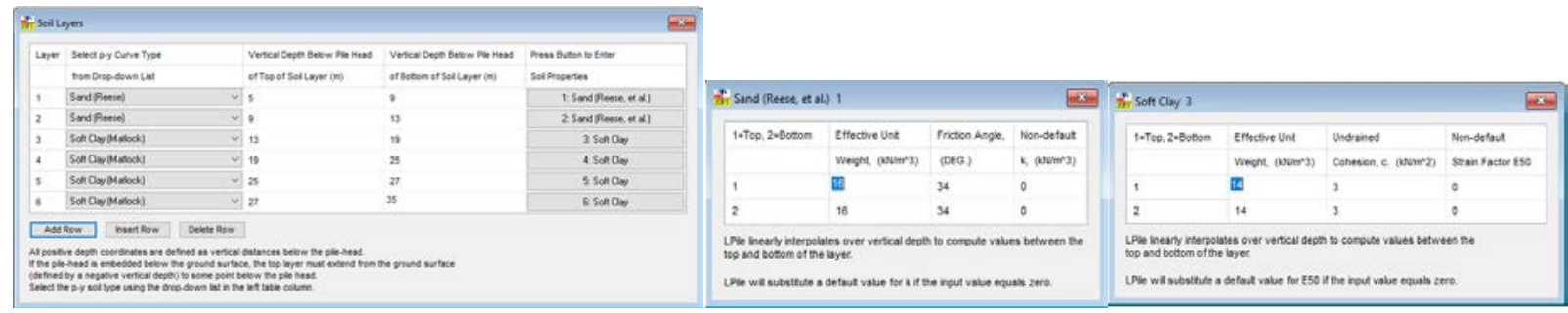

Gambar 4. Input Parameter Tanah pada Program LPILE

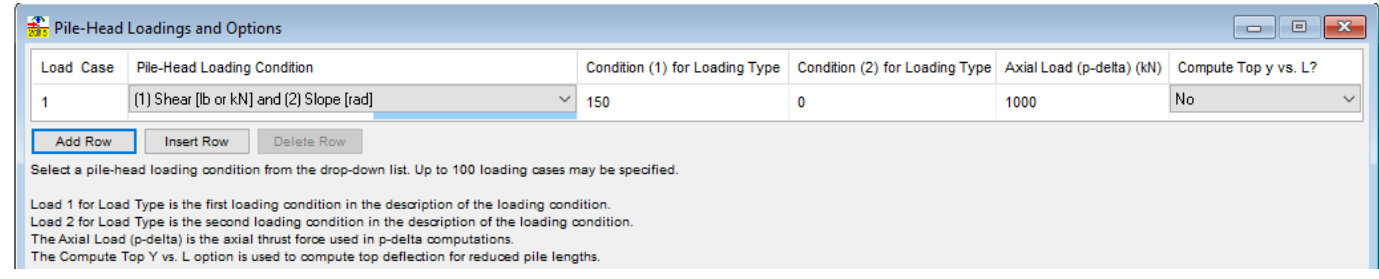

Gambar 5. Input Parameter Pembebanan pada Program LPILE

\section{Analisis dengan Program GRLWEAP}

Analisis dengan program GRLWEAP dilakukan untuk mengetahui kapasitas tiang, tegangan tiang dan karakteristik pemancangan tiang jika menggunakan hammer yang berbeda dari data awal. Analisis dilakukan dengan menggunakan hammer yang lebih besar dari data awal pada diameter tiang hasil trial pada program sebelumnya. Tegangan yang terjadi selama pemancangan tiang dengan menggunakan hammer yang berbeda akan dibandingkan dan diperiksa terhadap syarat tegangan untuk memastikan tiang tidak terjadi overstress dan overtension. Untuk mendapatkan hasil kapasitas dan tegangan, dilakukan dengan analisis driveability, lalu input jenis hammer, input parameter tiang, dan input parameter tanah. Parameter hammer berasal dari manufacturer hammer masing-masing.

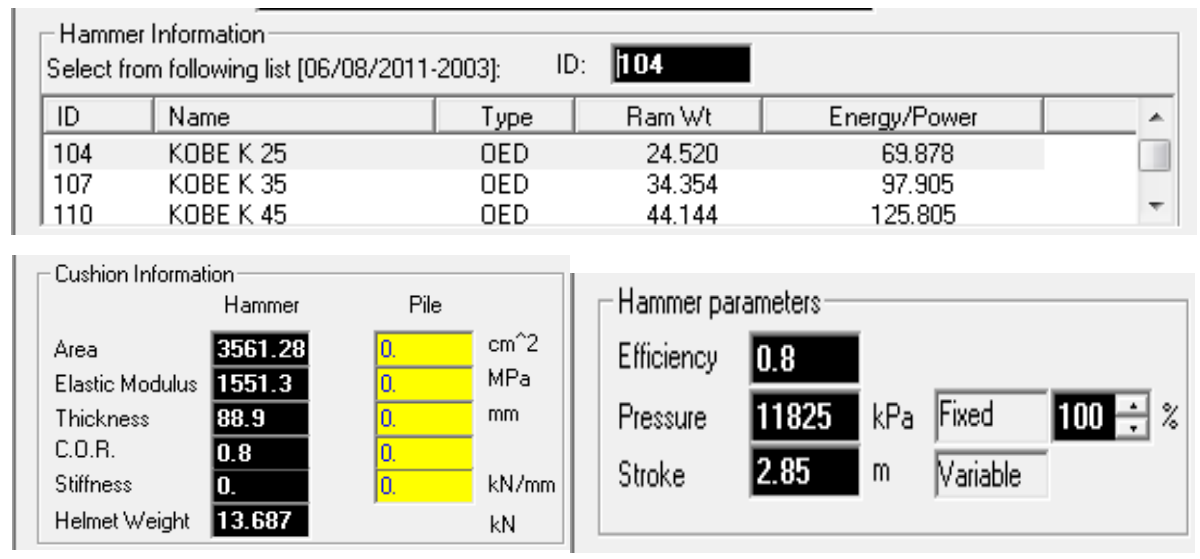

Gambar 6. Input Pemilihan Hammer dan Parameter Hammer

\begin{tabular}{|c|c|c|c|c|}
\hline$\left[\begin{array}{l}\text { Pile material- } \\
C \text { Concrete }\end{array}\right.$ & ( Steel & \multicolumn{3}{|c|}{ C Timber } \\
\hline \multicolumn{5}{|l|}{ - Pile Information- } \\
\hline Length & 30. & $\mathrm{~m}$ & Auto & Segments \\
\hline Penetration & 25. & $\mathrm{~m}$ & Auto. & S-Length \\
\hline Section Area & 293.55 & $\mathrm{~cm}^{\wedge} 2$ & Auto. & S-St, Wt \\
\hline Elast Modulus & 200000. & $\mathrm{MPa}$ & 0 & Splices \\
\hline Spec Weight & 77.5 & $\mathrm{kN} / \mathrm{m}^{\wedge}$ & 3 & \\
\hline Toe Area & 293.55 & $\mathrm{~cm}^{\wedge} 2$ & Pile 1 & ype: \\
\hline Perimeter & 1.885 & $\mathrm{~m}$ & Pipe & \\
\hline Pile Size & 600. & $\mathrm{~mm}$ & & \\
\hline
\end{tabular}

Gambar 7. Input Parameter Tiang 


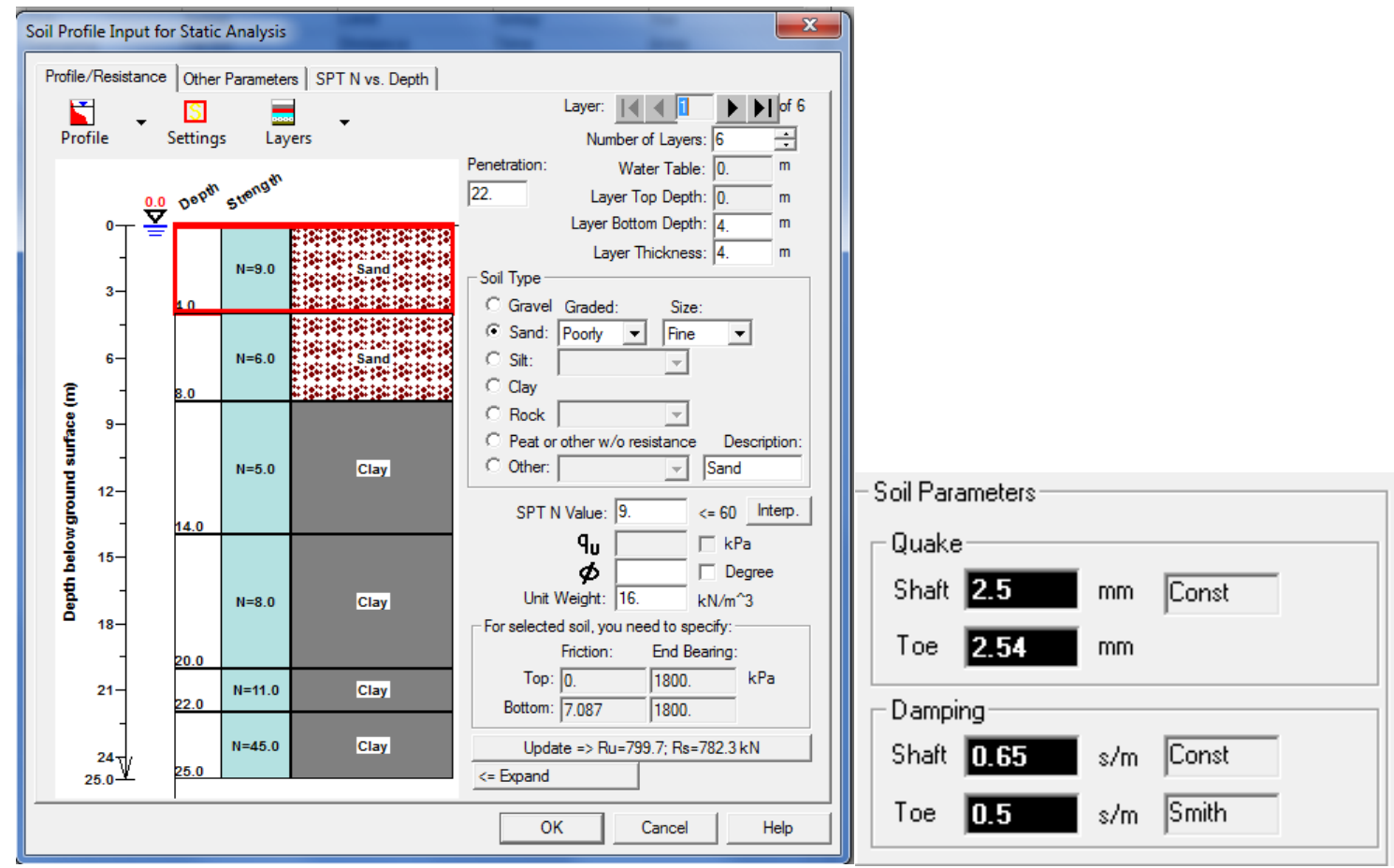

Gambar 8. Input Parameter Tanah

Untuk parameter tanah quake dan damping akan diisi secara otomatis oleh program GRLWEAP sesuai dengan jenis tanah yang digunakan pada simulasi. Quake merupakan nilai deformasi elastis maksimum tanah yang terjadi. Berikut merupakan tabel jenis tanah beserta dengan nilai quake dan damping menurut program GRLWEAP:

Tabel 5. Rekomendasi Nilai Quake Program GRLWEAP (Sumber: GRLWEAP Help)

\begin{tabular}{cllc}
\hline & \multicolumn{1}{c}{ Soil Type } & \multicolumn{1}{c}{ Pile Type or Size } & Quake (mm) \\
\hline Shaft Quake & All soil types & All Types & 2.5 \\
\hline \multirow{4}{*}{ Toe Quake } & All soil types, soft rock & $\begin{array}{l}\text { Non-displacement piles } \\
\text { i.e. driving unplugged }\end{array}$ & 2.5 \\
\cline { 2 - 4 } & Very dense or hard soils & $\begin{array}{l}\text { Displacement piles } \\
\text { diameter or width } D\end{array}$ & of \\
\cline { 2 - 4 } & Soils which are not very dense or hard & $\begin{array}{l}\text { Displacement piles } \\
\text { diameter or width D }\end{array}$ & of \\
\cline { 2 - 4 } & Hard Rock & All Types & 1 \\
\hline
\end{tabular}

Tabel 6. Rekomendasi Nilai Damping Program GRLWEAP (Sumber: GRLWEAP Help)

\begin{tabular}{ccc}
\hline & Soil Type & Damping Factor $\mathrm{s} / \mathrm{m}$ \\
\hline \multirow{2}{*}{ Shaft Damping } & Non-cohesive & 0.16 \\
\cline { 2 - 3 } & Cohesive & 0.65 \\
\hline \multirow{2}{*}{ Toe Damping } & In all soil types & 0.5 \\
\hline
\end{tabular}

\section{HASIL ANALISIS DAN PEMBAHASAN}

\section{Hasil Analisis dengan Program LPILE}

Analisis dari program LPILE berhasil dilakukan jika tidak ada pesan error dari program saat melakukan run analysis seperti pada gambar berikut: 


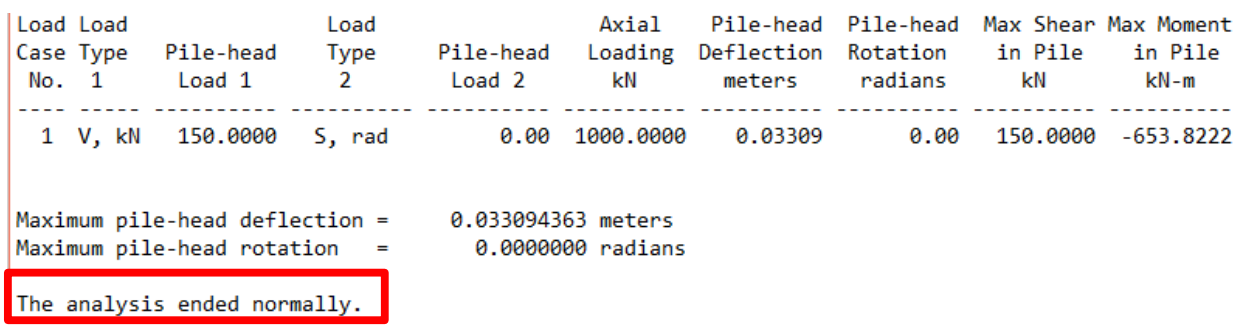

Gambar 9. Contoh run analysis tanpa pesan error

Nilai kapasitas tiang dapat dilihat dari notepad hasil run analysis program LPILE. Tanda "Y” pada keterangan menunjukkan bahwa tiang telah mencapai batas tegangan lelehnya. Kapasitas tiang dapat diketahui dengan membandingkan momen maksimum yang dapat terjadi pada tiang sebelum mencapai tegangan leleh terhadap nilai momen lentur maksimum. Jika nilai momen maksimum yang terjadi pada tiang lebih kecil dibandingkan dengan nilai momen maksimum yang dapat diterima oleh tiang, maka tiang tersebut telah memenuhi syarat dan dapat digunakan.

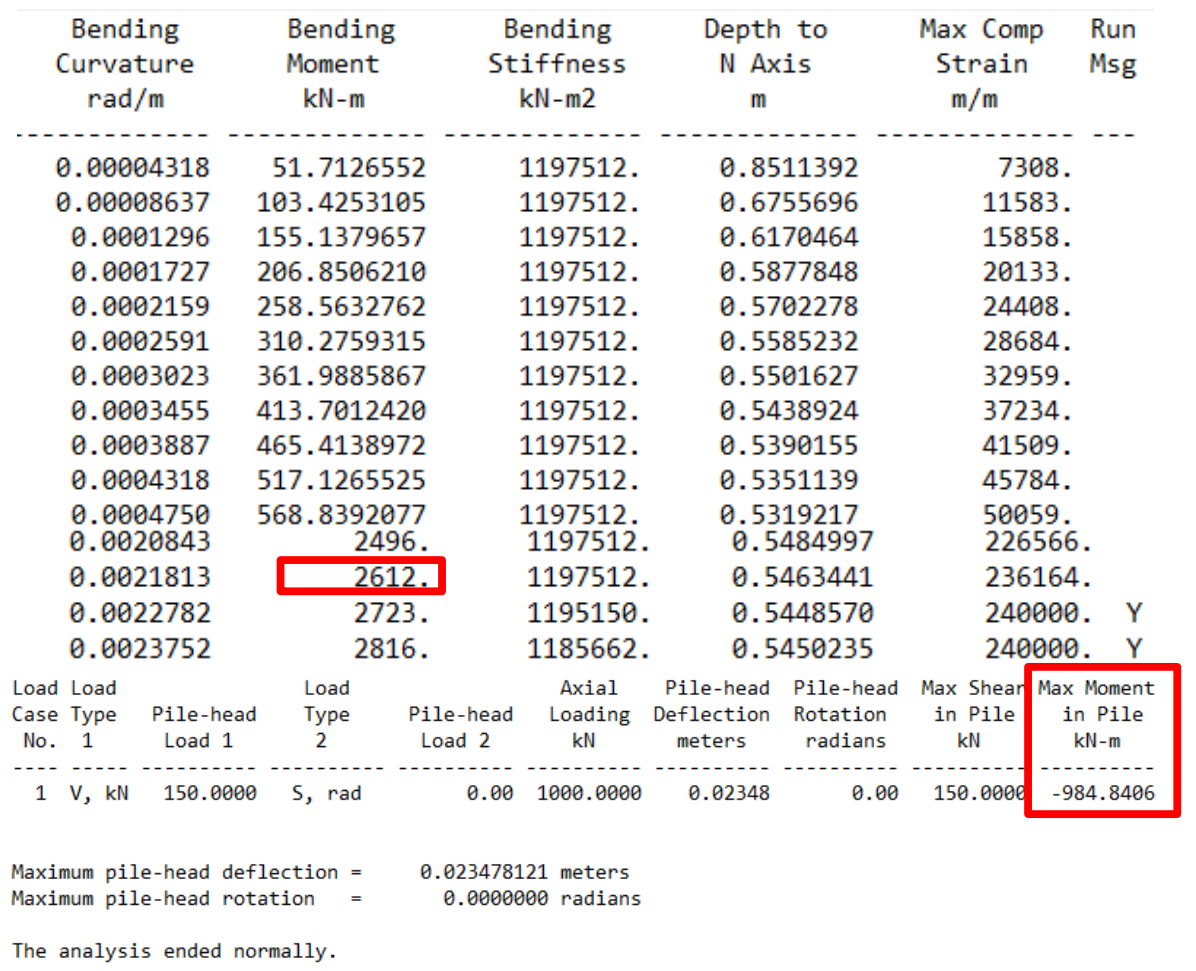

Gambar 10. Contoh Perbandingan Kapasitas Tiang dengan Momen Maksimum yang Terjadi

Output dari program LPILE juga menunjukkan nilai defleksi maksimum yang dapat terjadi pada tiang jika memperhitungkan adanya potensi gerusan dikemudian hari. Defleksi maksimum yang diperbolehkan adalah 25 mm. Contoh hasil defleksi maksimum pada kepala tiang dapat dilihat pada contoh gambar berikut:

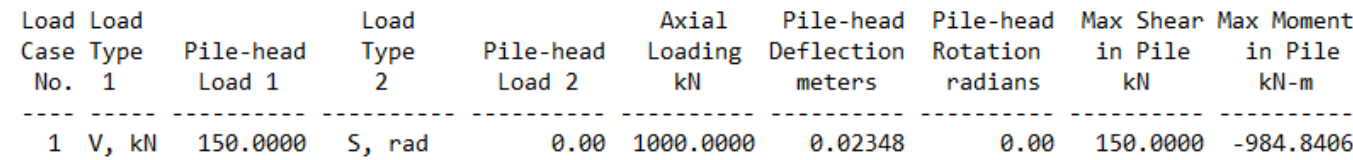

\footnotetext{
Maximum pile-head deflection $=\quad 0.023478121$ meters

Maximum pile-head rotation $=0.0000000$ radians
}

The analysis ended normally.

Gambar 11. Contoh Output Defleksi Maksimum Kepala Tiang 
Berikut merupakan tabel-tabel hasil analisis kapasitas tiang dan defleksi maksimum yang terjadi pada kepala tiang dengan trial diameter tiang akibat adanya efek gerusan:

Tabel 7. Hasil Kapasitas Tiang dan Defleksi Maksimum Akibat Efek Gerusan

\begin{tabular}{|c|c|c|c|c|}
\hline $\begin{array}{l}\text { Diameter Tiang } \\
(\mathrm{cm})\end{array}$ & Gerusan (m) & $\begin{array}{c}\text { Momen Maksimum } \\
(\mathrm{kNm})\end{array}$ & $\begin{array}{c}\text { Kapasitas Tiang } \\
(\mathrm{kNm})\end{array}$ & $\begin{array}{c}\text { Defleksi } \\
\text { Maksimum (cm) }\end{array}$ \\
\hline \multirow{4}{*}{60} & 0 & 653.8222 & 839.0738716 & 3.3094363 \\
\hline & 1 & 743.6343 & 839.0738716 & 4.7828464 \\
\hline & 2 & 845.3812 & 839.0738716 & 6.8841656 \\
\hline & 3 & 973.7067 & 839.0738716 & 10.1611443 \\
\hline \multirow{4}{*}{80} & 0 & 654.6857 & 1630 & 1.4136667 \\
\hline & 1 & 740.2589 & 1630 & 2.0150096 \\
\hline & 2 & 847.9661 & 1630 & 2.9993734 \\
\hline & 3 & 965.4956 & 1630 & 4.2767935 \\
\hline \multirow{4}{*}{100} & 0 & 676.9474 & 2612 & 0.8098823 \\
\hline & 1 & 761.8538 & 2612 & 1.1362795 \\
\hline & 2 & 869.6246 & 2612 & 1.6671209 \\
\hline & 3 & 984.8406 & 2612 & 2.3478121 \\
\hline
\end{tabular}

\section{Hasil Analisis dengan Program GRLWEAP}

Pada laporan output program GRLWEAP dapat diketahui kapasitas ultimit tiang, jumlah pukulan, tegangan tarik dan tekan yang terjadi saat pemancangan tiang, serta energi maksimum yang ditransfer pada kepala tiang. Output dari program GRLWEAP kemudian dibandingkan jika menggunakan hammer yang lebih besar. Berikut merupakan contoh dari hasil numerical dan grafik driveability program GRLWEAP:
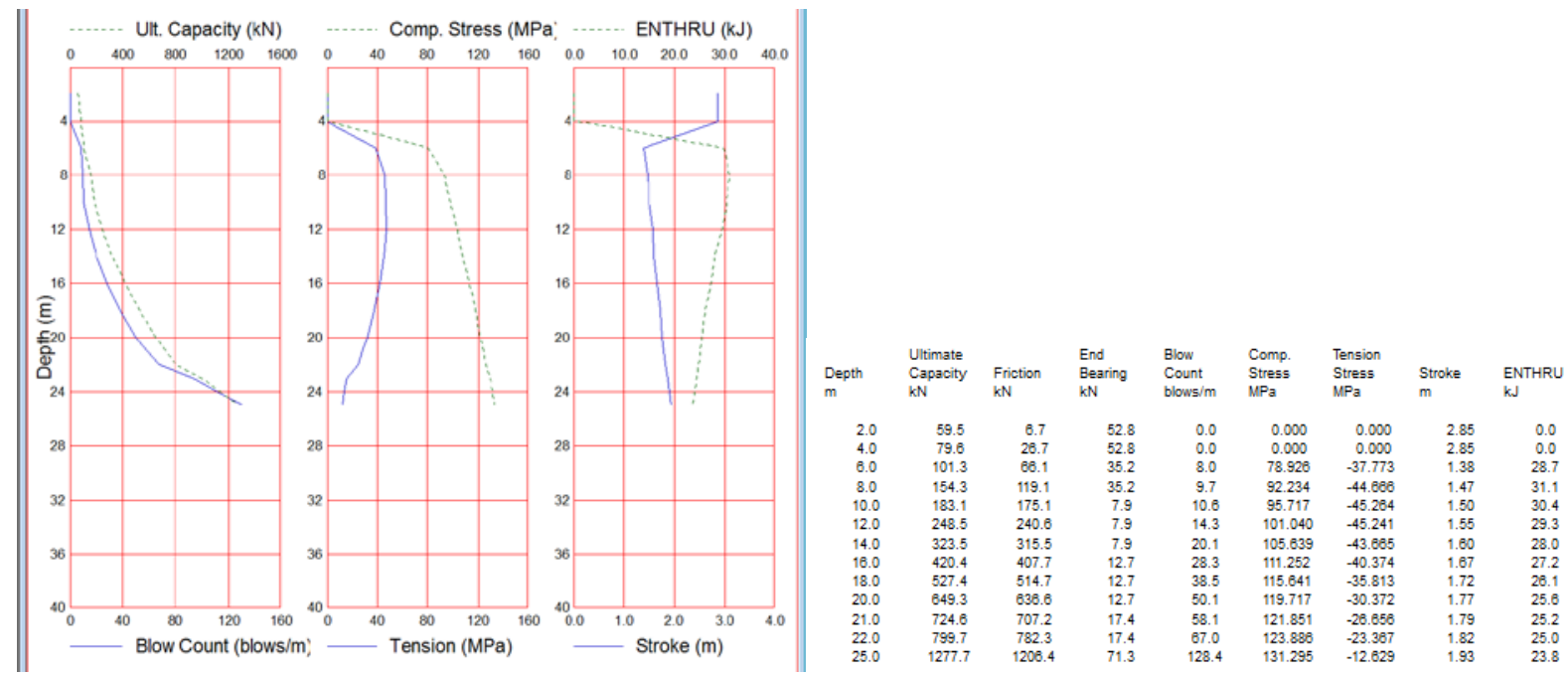

Gambar 12. Contoh output grafik driveability dan numerical dari program GRLWEAP

Pada gambar grafik yang pertama diketahui kapasitas ultimit tiang terhadap kedalaman pemancangan tiang serta jumlah pukulan hammer per meter. Pada gambar grafik kedua diketahui tegangan tarik dan tekan yang terjadi pada tiang saat dilakukan pemancangan. Pada grafik yang ketiga diketahui energi yang ditransfer pada kepala tiang selama dilakukan pemancangan di lapangan.

Pada gambar hasil numerical program dapat diketahui lebih tepat lagi berapa besaran nilai-nilai yang diperoleh dari simulasi pemancangan tiang. Berikut merupakan tabel hasil dari simulasi pemancangan dengan menggunakan hammer yang berbeda serta mengikuti hasil trial diameter pada program sebelumnya. 
Tabel 8. Output Simulasi Pemancangan dengan Trial Hammer

\begin{tabular}{ccccccc}
\hline $\begin{array}{c}\text { Ukuran } \\
\text { Tiang }\end{array}$ & Jenis Hammer & $\begin{array}{c}\text { Kapasitas Ultimit } \\
(\mathrm{kNm})\end{array}$ & $\begin{array}{c}\text { Jumlah } \\
\text { Pukulan }\end{array}$ & $\begin{array}{c}\text { Tegangan } \\
\text { Tarik (MPa) }\end{array}$ & $\begin{array}{c}\text { Tegangan } \\
\text { Tekan (MPa) }\end{array}$ & $\begin{array}{c}\text { Tegangan Ijin } \\
(\mathrm{MPa})\end{array}$ \\
\hline \multirow{2}{*}{$60 \mathrm{~cm}$} & KOBE K 25 & 1277.7 & 128.4 & 12.629 & 131.295 & \\
\cline { 2 - 5 } & KOBE K 35 & 1277.7 & 85.9 & 15.885 & 153.163 \\
\hline \multirow{2}{*}{$80 \mathrm{~cm}$} & KOBE K 25 & 1704.1 & 200 & 21.841 & 126.63 & \multirow{2}{*}{216} \\
\cline { 2 - 6 } & KOBE K 35 & 1704.1 & 131 & 21.573 & 150.889 & \\
\hline \multirow{2}{*}{$100 \mathrm{~cm}$} & KOBE K 25 & 2130.4 & 290.7 & 23.421 & 120.9 \\
\cline { 2 - 5 } & KOBE K 35 & 2130.4 & 184.5 & 23.900 & 143.708 \\
\hline
\end{tabular}

Dari hasil tegangan tarik dan tegangan tekan yang terjadi pada tiang dengan trial hammer KOBE K 25 dan KOBE K 35 , lalu akan dibandingkan dengan tegangan tarik dan tegangan tekan ijin untuk material tiang baja dengan $\mathrm{f}_{\mathrm{y}} 240$ MPa. Menurut program GRLWEAP tegangan tarik dan tegangan tekan ijin material tiang baja, dapat diperiksa dengan seperti berikut:

dengan $\mathrm{f}_{\mathrm{y}}=$ tegangan leleh material baja

$$
\sigma_{i j i n}=0,9 . f_{y}
$$

\section{KESIMPULAN}

1. Dari hasil simulasi program LPILE, dapat diambil kesimpulan bahwa jika terjadi scouring sedalam 3 meter, maka tiang akan mengalami pertambahan momen lentur, dan defleksi tiang yang lebih besar jika dibandingkan dengan tidak terjadinya scouring pada sekitar tiang. Hasil tersebut dapat dilihat pada Tabel 7.

2. Diameter tiang yang semakin besar dapat mempengaruhi kapasitas tiang dan defleksi tiang tersebut. Ukuran tiang $100 \mathrm{~cm}$ merupakan tiang dengan defleksi kepala tiang yang terkecil serta memenuhi syarat defleksi yaitu $25 \mathrm{~mm}$. Hasil tersebut dapat dilihat pada Tabel 7. Dari hasil simulasi program juga dapat disimpulkan bahwa diperlukannya kapasitas tiang yang lebih besar agar struktur atas tidak dapat mengalami kerusakan yang membahayakan.

3. Dari hasil simulasi program GRLWEAP, dapat diambil kesimpulan bahwa jika menggunakan hammer yang lebih besar, tegangan yang terjadi pada tiang juga akan membesar, hal ini patut diwaspadai karena dapat terjadi overstress maupun overtension pada tiang. Hasil tersebut dapat dilihat pada Tabel 8.

4. Dari hasil simulasi program GRLWEAP, dapat diambil kesimpulan bahwa ukuran hammer yang berbeda dengan diameter tiang yang sama tidak mempengaruhi kapasitas ultimit tiang tersebut. Dan jika menggunakan hammer yang lebih besar, jumlah pukulan terhadap tiang akan mengecil dan hal ini dapat mempercepat waktu pemancangan di lapangan dikarenakan penetrasi tiang akan lebih mudah dicapai dibandingkan dengan menggunakan hammer yang lebih kecil. Hasil tersebut dapat dilihat pada Tabel 8.

\section{DAFTAR PUSTAKA}

Das, B. (1995). Mekanika Tanah (Prinsip-prinsip Rekayasa Geoteknis). Jakarta: Penerbit Erlangga.

Budhu, M. (2000). Soil Mechanics and Foundations. Unites States of America: John Wiley \& Sons, Inc.

LPILE 2018 - User's Manual. (2018). A Program to Analyze Deep Foundations Under Lateral Loading. Texas: Ensoft,Inc.

Lujito, Purwantoro. D., dan Sudiyono. (2015). Gerusan di Sekitar Dua Pilar Jembatan dan Upaya Pengendaliannya. Peneltian, Universitas Negeri Yogyakarta.

Miller, W. (2003). Model For The Time Rate Of Local Sediment Scour At A Cylindrical Structure. Disertasi, University of Florida.

Sardjono H.S. (1984). Teknik Pondasi Bagian 1, Yogyakarta: Universitas Gajah Mada. 